\title{
AN APPLICATION OF IMPACT CALCULATION METHOD IN TRANSPORTATION
}

\author{
Agnes WANGAI ${ }^{1,2 *}$, Utku KALE ${ }^{3}$, Sergey KINZHIKEYEV ${ }^{4}$ \\ ${ }^{1,3,4}$ Dept of Aeronautics, Naval Architecture and Railway Vehicles, Budapest University of Technology \\ and Economics, Budapest, Hungary \\ ${ }^{2}$ Dept of Electrical and Electronics Engineering, Dedan Kimathi University of Technology, Nyeri, Kenya
}

Received 28 May 2018; revised 29 March 2019, 7 July 2019; accepted 22 September 2019

\begin{abstract}
Forecasted/projected rise of impacts in modes of transportation has necessitated a new rethinking of the evaluation of total impact. While most researchers deal with defined parts (like environmental impact) of the total impact. The total impact calculation methodology includes: (1) analysis of all the impacts (environmental impact, safety and security, costs, cost benefits and sustainability), (2) evaluation on the transportation system level, (3) as their total value (including all the related sub-systems and elements, i.e. transport infrastructure, transport flow control), (4) generation of total impact index. Such an index might be called as transport total sustainability index. The paper defines the Total Impact Performance Index (TIPI) evaluating the total impact in the form of generalized (summarized) costs, specifies its calculation methodology, develops a simplified Excel based calculation methods. It aims to demonstrate the applicability of this methodology, which involves evaluation of impacts in more detailed forms, two parts calculation methods namely impact of road transport safety aspects and impact of the railway transport. Finally, some selected results of the applied new index calculation and developed methodology are introduced and analysed.
\end{abstract}

Keywords: total impact performance index, greenhouse gas, emission, transportation, impacts evaluation, external costs, safety aspect.

\section{Notations}

$\mathrm{CO}_{2}$ - carbon dioxide;

$\mathrm{CO}_{2 \mathrm{e}}$ - carbon dioxide equivalent;

GDP - gross domestic product;

GHG - greenhouse gas;

GI - group of impact;

pkm - passenger-kilometre;

SGI - sub-group of impact;

TILCC - total impact life-cycle cost;

TIPI - total impact performance index;

tkm - tonne-kilometre;

TLCC - total life-cycle cost;

TLCW - total life-cycle work;

TM - transport mean;

TOLCC - total operational life-cycle cost;

TOPI - total operation performance index;

TPI - transportation (total) performance index;

train-km - train-kilometre;

vkm - vehicle-kilometre;

VMT - vehicle miles travelled;

VPC - value of preventing a casualty;

WTP - willingness-to-pay.

\section{Introduction}

For the last two decades, sustainability has become a top constraint on new technology and system developments. The most widely known definition "sustainable development is the development that meets the needs of the present without compromising the ability of future generations to meet their own needs" (WCED 1987). Here are two essential key-concepts: (1) needs that should be met and (2) the "idea of limitations imposed by the state of technology and social organization on the environment's ability to meet present and future needs" (WCED 1987). By use of this principle, the analysis and evaluation of the impact of developing new technologies, new technical, technological, social, ecological systems on the environment, safety, security, applied resources, etc. are emerging as important and required part of feasibility studies, comparison of the available technologies and systems.

This paper is associated with the research by Rohács, J. and Rohács, D. (2020) introduces special index for total impact analysis calculated in forms of total external costs

*Corresponding author. E-mail: awangai@vrht.bme.hu 
generated by using the transportation system. It develops a practical method for realization the total impact calculation described in the research by Rohács, J., Rohács, D. (2020). The developed methodology was used for investigation and comparison of total impact of conventional and electric cars operating in US and EU (Wangai et al. 2017).

The most important novelties of developing and applying the method in this paper are as follows:

- all the impact (environmental impact, safety and security, cost, cost benefits and sustainability) are analysed and taken part in total impact calculation;

- the total impacts are evaluated on the transportation system level allowing to make a comparison of the different transportation means;

- the value of the total impact summarizes all the impacts including all the related sub-systems and elements, i.e. vehicle operation, production, maintenance, construction, operation and maintenance of the required infrastructure, traffic organization and control, safety and security aspects, effects of accidents, emissions, noise on the human health, effects on nature and on built and cultural heritages that makes possible to analyse the impact generated by the transport companies, vehicle fleets, fleet mix or even vehicle types, so a unique TIPI calculation methodology that is developing.

The paper defines the TIPI evaluating the total impact in form of generalized (summarized) cost, specifies its calculation methodology, develops a simplified Excel based calculation methods and underlines the constraints of the applicability. As can be seen, the developed methodology is well general, while its application requires adaptation to the given regions, level of economy and social conditions.

The applicability of the developed methodology is demonstrated by two major examples: (1) analysis of calculation the safety aspects generating external costs in road transport and (2) index calculation for railway transport.

\section{Some thoughts on total impact}

Development of sustainable transport is the central element and key objective of vision and programs of the future transport development generally (EC 2011c) and on the TMs level (ACARE 2001; EC 2011b; ACARE 2017), too. In efforts to achieve sustainable transport, the numbers researchers in this field is growing exponentially as evident in Figure 1 and also trending within google users.

Litman (2019) well-known as indicator developer for study sustainable transport defines the goals of sustainable transport from economic (efficient mobility, local economic development, operational efficiency), social (social equity (fairness), human safety and health, affordability, community cohesion, cultural preservation) and environmental (air, noise and water pollution reductions, climate change emissions, resource conversation, openspace preservation, biodiversity protection) point of view. a)

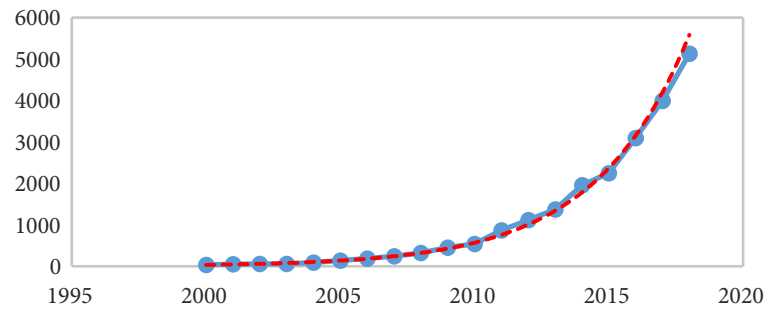

b)

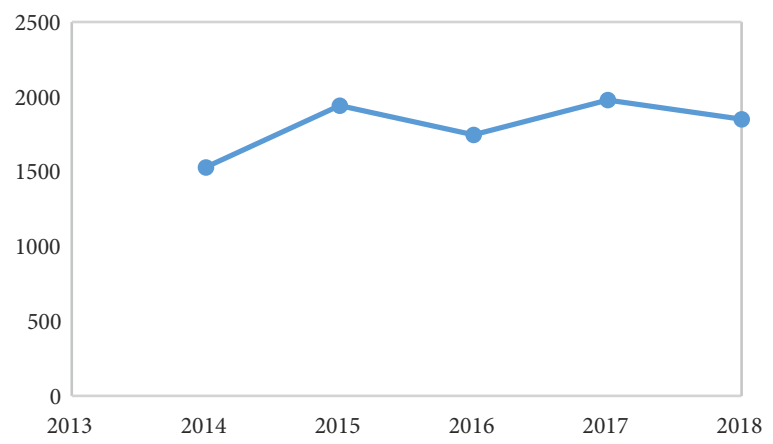

Figure 1. Scientific output indexed by Web of Science (a) and Google (b) searches relating to transport impacts (data retrieved on 15 March 2019)

The EC (2011a) adds to this list a further area: governing and good planning. Such an approach to impact analysis is applied by EC (2011a) on impact assessment.

Other interesting and important study published by Chester and Horvath (2009) on investigation the lifecycle energy, GHG emissions, namely they had taken into account the emissions caused by infrastructure, fuel production, and supply chains. They found, for example, that total life-cycle energy inputs and GHG emissions contribute an additional $63 \%$ for on the road, $155 \%$ for rail, and $31 \%$ for air systems over vehicle tailpipe operation. The total energy consumption for pkm travelled [MJ/ $\mathrm{pkm}]$ and total $\mathrm{GHG}$ emission in $\mathrm{CO}_{2}$ equivalent $\left[\mathrm{g} \mathrm{CO}_{2 \mathrm{e}} \mathrm{l}\right.$ $\mathrm{pkm}$ ] calculated for rail transport (Figure 2) demonstrate the meaning and major aspects of this approach in impact calculation. As it can be seen, the ratio of operation and total energy consumption and $\mathrm{CO}_{2 \mathrm{e}}$ emission of rail transport are small (actually they are the smallest between the transportation means), because the required large infrastructure. Another important aspect calling the attention is the large differences between rail transport operated in different regions. The $\mathrm{CO}_{2 \mathrm{e}}$ emitted by the Boston light rail rather greater than emitted by light rail operated in San Francisco, because in California $49 \%$ of electricity is fuel-based generated, while in Massachusetts the same ratio reaches the $82 \%$

External costs as defined by Bickel and Friedrich (2005) as "an external cost arises, when the social or economic activities of one group of persons have an impact on another group and then that impact is not fully accounted, or compensated for, by the first group". They are usually estimated indirectly using such methods as WTP for avoiding, mitigating or controlling particular impacts (Tánczos, Török 2006; Ghadi et al. 2018). Different 
a)

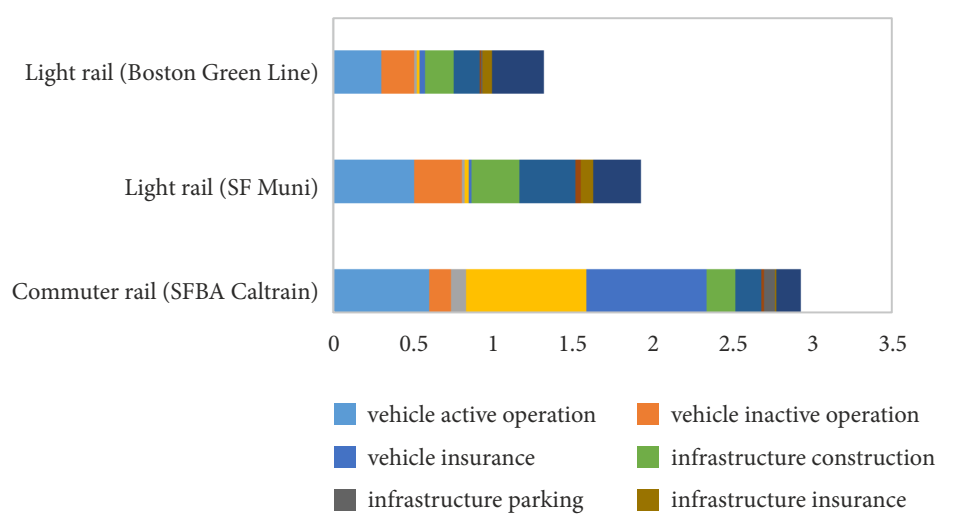

b)

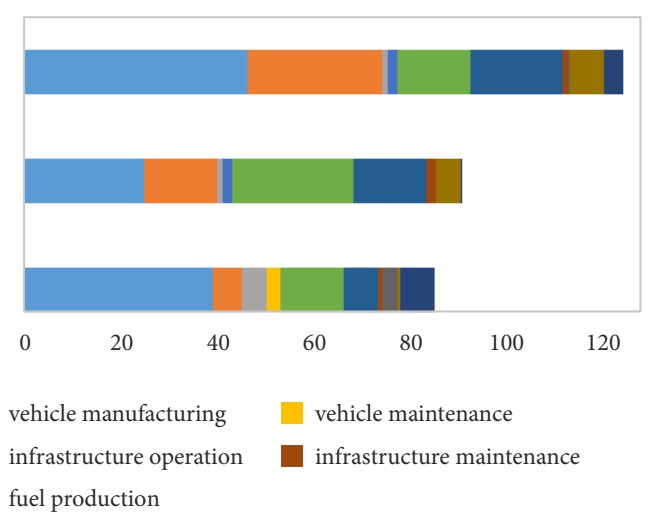

Figure 2. Total energy consumption (a) in $[\mathrm{MJ} / \mathrm{pkm}]$ and total $\mathrm{CO}_{2 \mathrm{e}}$ emission (b) in $\left[\mathrm{g} \mathrm{CO}_{2 \mathrm{e}} / \mathrm{pkm}\right]$ of selected rail transport (redrawn by use of data from Chester and Horvath (2009))

approaches have been utilized to reduce externalities, for example: using a freight transport model to promote sustainable logistics by simulating the impact use of night freight distribution (Mommens et al. 2018), estimating the emission caused by the vehicle flow (Janic 2007), and in interrelation of external effects as explained, in case of road congestion and noise, a temporally change of flow, i.e. during off-peak times noise should be reduced by concentrating traffic flow along main roads while during peak times congestion reduction is achieved by shifting transport users to smaller roads (Kaddoura, Nagel 2018).

The results of the European and national actions, projects are well summarized and integrated into the researches by Van Essen et al. (2011), Maibach et al. (2008) and Ricardo-AEA (2014). The authors of these reports made a very hard work documented by large number of citations that allows to understand and find the required sources for adaptation of methodology described by this paper.

The Dept of Aeronautics, Naval Architecture and Railway Vehicles of the Budapest University of Technology and Economics (Hungary) had been involved into several large national and international projects investigating the sustainability, sustainable transport development and developing the radically new technologies required complex impact analysis (Rohács, Simongáti 2007; Rigo et al. 2007; Bicsák et al. 2012; Rohacs 2010; Rohacs et al. 2013; Rohacs, D., Rohacs, J. 2016). These studies and developing skills and competencies in impact calculations have led to initiating a general work on creating the methodology for total impact calculations. This paper describes the first results of this project.

\section{TIPI}

The definition and method of evaluation of the total impact that applies in this methodology development were introduced by reference (Rohács, J., Rohács, D. 2020). The simplified and unique index evaluating the total impact is given in form of total cost induced by all life-cycle effects of the transportation system in the form of related to a unit of transport work ([pkm] or [tkm]):

$$
T P I=\frac{T L C C}{T L C W}=\frac{T O L C C}{T L C W}+\frac{T I L C C}{T L C W}=T O P I+T I P I,
$$

where: TPI is the total performance index; TOPI is the total operation performance index; TIPI is total impact performance index; TLCC is the total life-cycle cost; TOLCC is the total operational life-cycle cost; TILCC is the total impact life-cycle cost; TLCW is the total life-cycle work.

The TOPI defining the operational cost of the given vehicle, given transportation mode, is well-known and applied by owners, operators, service providers. They use it in selecting the aircraft, evaluation of the mixed fleets determining the optimized transportation chain. While, principally, the TIPI deals with the externality. This is the index that might be used in impact assessment.

The TIPI summarizes all the impacts (Rohács, J., Rohács, D. 2020):

$$
T I P I=\sum_{i=1}^{n} T I P I_{i}=\frac{\sum_{i=1}^{n} T I L C C_{i}}{T L C W},
$$

where: $i=1,2, \ldots, n$ define the different groups of impact. In the case of transportations systems, $i$ can be defined as: safety and security, environmental impacts, system peculiarities, system support, use of resources.

The TIPI for GIs can be determined as sum of the different effects (Rohács, J., Rohács, D. 2020):

$$
\begin{aligned}
& \operatorname{TIPI}_{i}=\frac{a}{T L C W_{i}} \forall i ; \\
& \operatorname{TLCW}_{i}=\sum_{j=1}^{m} \sum_{k=1}^{l} \sum_{q=1}^{r} N_{j, k, q} \cdot W_{j, k, q},
\end{aligned}
$$

where:

$$
a=\sum_{j=1}^{m} \sum_{k=1}^{l} \sum_{q=1}^{r} N_{j, k, q} \cdot p_{j, k, q} \cdot I_{j, k, q} \cdot \sum_{v=1}^{u} o_{j, k, q, v} \cdot c_{j, k, q, v},
$$

where: $j=1,2, \ldots, m$ describes the subgroups of impact; $k=1,2, \ldots, l$ defines the TMs; $q=1,2, \ldots, r$ represents the types or groups of the given transportation system; $v=1$, $2, \ldots, u$ identifies the different forms of consequences; $N$ 
is the number of sub-group elements contributing to the impact; $q, p$ is the parameter of the given types or groups of system elements that cause the investigated effects; $I$ is the impact indicator of the given system element; $o$ the outcomes / consequences of the impact defined by $I$ or caused by the events, situations related to the $I$ indicator; $c$ is the conversion coefficient to assess the (external) cost; $W$ is the work done during the investigated period defined by $p$. It means, if the $p$ is the parameter of function given in the form of average annual unit, then the $W$ should be related to the year, too. For example, if the $N$ defines the number of vehicle and $p$ is the annual average running of the vehicles, then the $W$ equals to $p$.

The $p$ parameter acts as the weighting coefficient, or weighting function, too. Of course, it depends on goals and level of studies and on the vehicle or system characteristics, parameters defined by the applied indicators. The consequences, $o$, namely function of consequences take into account the outcomes form the impact characterized by the performance indicator. The consequences might be divided into more forms harmonized with the applied impact indicators. For example, a simple accident may cause damages in (1) vehicle, (2) transport infrastructure, (3) buildings, (4) cultural values, etc. and human casualty might be classified, too, as a fatality, severe and slight injury. The consequences are defined as a function of outcomes because they depend on the level of economy and may change during the life-cycle frame.

With taking into account the functions of parameters, impact indicators, consequences and conversation coefficients, following to the research by Rohács, J. and Rohács, D. (2020), the Equation (3) can be rewritten in several other forms:

$$
\operatorname{TIPI}_{i}=\frac{a_{1}}{T L C W_{i}} \forall i,
$$

where:

$$
\begin{aligned}
& a_{1}=\sum_{j=1}^{m} \sum_{k=1}^{l} \sum_{q=1}^{r} N_{j, k, q} \cdot f_{p_{j, k, q}}\left(p_{j, k, q}\right) \cdot f_{I_{j, k, q}}\left(I_{j, k, q}\right) \times \\
& \sum_{v=1}^{u} f_{o_{j, k, q, v}}\left(o_{j, k, q, v}\right) \cdot f_{c_{j, k, q, v}}\left(c_{j, k, q, v}\right) ; \\
& T I P I_{i}=\frac{a_{2}}{T L C W_{i}} \forall i,
\end{aligned}
$$

where:

$$
\begin{aligned}
& a_{2}=\sum_{j=1}^{m} \sum_{k=1}^{l} \sum_{q=1}^{r} N_{j, k, q} \cdot f_{p_{j, k, q}}\left(p_{j, k, q}\right) \times \\
& \sum_{v=1}^{u} f_{I}\left(I_{j, k, q, v}\right) \cdot f_{o_{j, k, q, v}}\left(o_{j, k, q, v}\right) \cdot f_{c_{j, k, q, v}}\left(c_{j, k, q, v}\right),
\end{aligned}
$$

where: $f$ are functions depending on the given index $x$ (namely $P, I, o, c$ ) at the defined next indexes.

These methods developed for TIPI calculations can be applied to vehicle, equivalent vehicle, fleet, or to the transportation company, TMs, and so on. Therefore, this methodology is structured in a hierarchic form. For example, in very first approximation, the safety impact of accidents as external costs can be determined by use of the following simple formula for a city bus company (Rohács, J., Rohács, D. 2020):

$$
\begin{gathered}
T I P I_{\text {safety, accident }}=\frac{\sum_{i=1}^{n} N_{i} \cdot p_{i} \cdot I_{s a, i} \cdot \sum_{j=1}^{k} o_{i, j} \cdot c_{i, j}}{\sum_{i=1}^{n} N_{i} \cdot p_{i}}= \\
\sum_{i=1}^{n} N_{i} \cdot p_{i} \cdot I_{s a, i} \cdot\left(o_{i, d} \cdot c_{i, d}+o_{i, i n} \cdot c_{i, i n}+o_{i, f} \cdot c_{i, f}\right)
\end{gathered}
$$

where: $i=1,2, \ldots, n$ defines the types of the buses at company; $N_{i}$ number of buses of given types; $p_{i}$ is the annual average running of the $i$ type of buses; $I_{s a, i}$ safety accident rate (risk) of the given type of busses; $o_{d}, o_{i n}, o_{f}$ are the weighting coefficient, ratio of damage, injure and fatal accidents taking into account the third parties involved in the accidents (therefore, the sum of the weighting coefficients is more than 1$) ; c_{d}, c_{i n}, c_{f}$ are the cost conversion coefficients of damage, injuries and fatalities.

\section{Developing Excel tool for index calculation}

After investigation of the possible use of the developed model an Excel table, model was created. Excel software was considered because it's a simple useful tool for statistical analysis when dealing with large data set and was readily available. This was in efforts to create a user-friendly tool. Applying the tool, it must be adapted to the real calculation by (1) define the goals, (2) size and (3) level of investigation, as well as (4) possible sources of data, (5) economic and (6) societal conditions.

Principally all the required information might be defined, derived from the existing statistical data, references, research reports - EC (2011a); Ricardo-AEA (2014); Rohács, Simongáti (2007); Rigo et al. (2007); Bicsák et al. (2012); Rohacs (2010). However, the data very sensitive to the real situations, including the economy, culture, etc. of the region or country investigated. Therefore, this paper introduces the developing Excel table for TIPI calculation and demonstrates its applicability on an example of the TIPI $\left(\right.$ TIPI $\left._{\text {safety }}\right)$. The describing methodology is based on Equations (4) and (5).

The developed Excel table contains the following columns:

- number of rows;

- region or area of investigation (like Europe, or Hungary, or it might be a large or even small company as Budapest Mass Transport Company, or small logistic company, etc.);

- code number - completed from the indexes;

- GI (depicted by index $i$, in this example $i=1$ mean safety and security);

- SGI (identified by index $j$, where $j=1$ is safety);

- TMs (indexed by $k, k=1,2, \ldots$; namely road, railway, water, and air transport that might be divided into 
more subgroups, because the road transport contains the city or urban transport highway transport, rural transport, or cars, buses, light and have vehicles, the water transport can be classified as inland water navigation and marine transport, passengers and cargo ship transport, etc.);

- number of studied elements or merit, i.e. value of the chosen governing parameter (for example, number of cars in the given regions - it is well understood, the number of elements as usually can be derived from the available statistics like WRI (2018));

- applied general parameter (in this first application, the safety can be characterized by a number of accident of the investigated cars in defined regions, that can be calculated as the multiplication of the number of cars by general parameter as average running distance by general impact factor as average risk of accident);

- applied parameters, their appellations and values (for each parameter that defines - here - the general average running distance pro year);

- formula (using for determining the general parameter by use of defined, applied parameters) and calculated values;

- general impact indicator;

- applied indicators, their appellations and values (that defines the general impact);

- formula (using for determining the general impact indicator) and its calculated value;

- outcomes (determined by use of same methods as it applied to thegeneral parameter and general impact indicator calculations);

- cost coefficient (determined by use of same methods as it applied to the general parameter and general impact indicator calculations);

- work (two columns: dimension and value);

- results (summarized in 5 columns: TIPI $_{i, j, k, q}, T I P I_{i, j, k}$, TIPI $_{i, j}, T I P I_{i}$, and TIPI);

- the developing Excel table can be used if the parameters, impact indicators, outcomes, etc. will be defined and calculated.

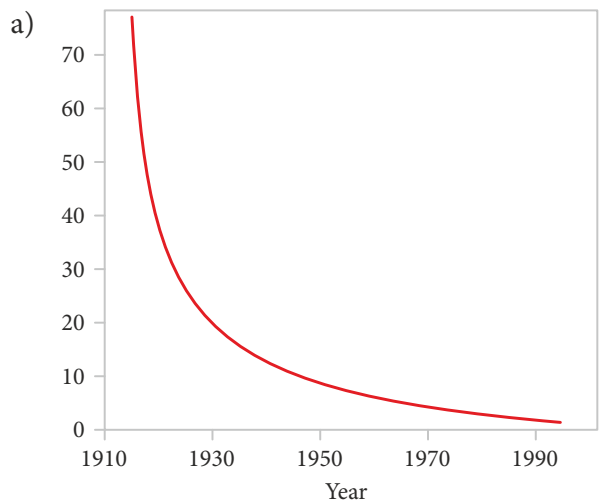

\section{Road transport safety aspects}

Road transport safety, safety aspects are investigated by many important papers. However, most of these papers use the statistical approach that may not results in the identification of the required most important parameters and indicators.

For example, most commonly indicator for road transport accident is the number of death in traffic accidents per million $\mathrm{km}$ (miles) of driven (Figure 3 redrawn by use of data from CORDIS (2006)). This indicator demonstrates the excellent work done by developers; the safety is increasing. Another representation of the data (Figure 3) shows not such a nice picture. So, the new, more dynamic and more safer cars are driven by users not so carefully.

In any case, it seems, the number of driving license is the best road traffic safety indicator.

By using the traditional approach, road traffic accidents can be determined as a multiplication of the number of cars $N$, average driven distance $p$ and safety indicator $I$ : $N \cdot p \cdot I$. The driven distance, of course, depends on many different aspects. In this study the driven distance was determined by use of three major parameters: $p_{1}$ - travel money budget or personal net income; $p_{2}$ - population density; $p_{3}$ - level of urbanization. The risk of accident of passenger cars, was calculated by applying the following impact indicators: $I_{1}$ - GDP; $I_{2 a}, I_{2 b}$ - ratio of highway and city roads in total road system; $I_{3 a}, I_{3 b}$ - ratio of young (less than 25 years) and old (more than 70 years old) car drivers. These parameters and impact indicators can be estimated by use of public statistical data, for example, WRI (2018); EU (2016); World Bank (2018); Eurostat (2018); BTS (2018); OECD (2018) and researches by Edenhofer et al. (2014); Litman (2019); Chester, Horvath (2009); Bickel, Friedrich (2005); Tánczos, Török (2006); Ghadi et al. (2018); Mommens et al. (2018); Janic (2007); Kaddoura, Nagel (2018); Van Essen et al. (2011); Maibach et al. (2008); Ricardo-AEA (2014); CORDIS (2006); Bickel et al. (2006); De Ceuster et al. (2004); Dobranskyte-Niskota et al. (2007); Messagie et al. (2013); Horvath, Matthews (2005); Santero et al. (2010); Santos et al. (2010);

b)

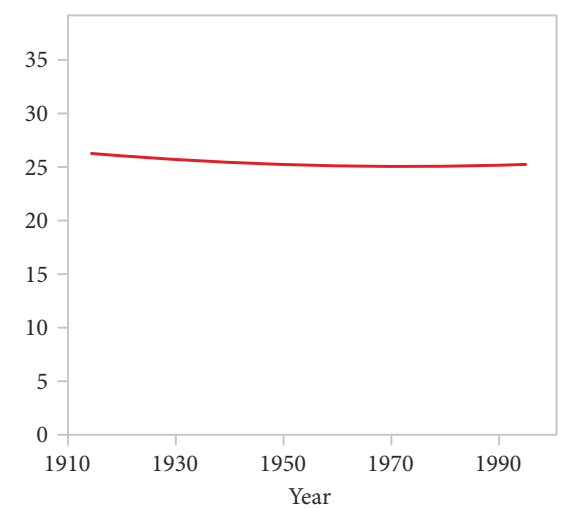

Figure 3. Changes in road transport safety indicators depending on proportion to different basis: $\mathrm{a}$ - death in traffic accidents per 100 million miles driven; $\mathrm{b}$ - death in traffic accidents per 100 thousand registered drivers (redrawn by use of data from CORDIS (2006)) 
Anas, Lindsey (2011), and making excellent discussions on the available initial information, as well as the papers publishing real applications by Ghadi et al. (2018); Van Essen et al. (2011); Maibach et al. (2008) and results of special investigations by Csikós et al. (2015); Tánczos, Török (2006); Hellgren (2007); Furch (2016); Jun, Kim (2007).

There were used the following type of models:

$$
\begin{aligned}
& P=\frac{k_{p} \cdot p_{1}^{\alpha}}{p_{2}^{\beta}} \cdot p_{3}^{\gamma} ; \\
& I=\frac{k_{I}}{I_{12}^{\alpha}} \cdot I_{2 a}^{\beta_{a}} \cdot I_{2 b}^{\beta_{b}} \cdot I_{3 a}^{\gamma_{a}} \cdot I_{3 b}^{\gamma_{b}},
\end{aligned}
$$

where: $k$ are the coefficients and $\alpha, \beta, \gamma$ are the model parameters depending on the TMs, vehicle type and might be modified depending on the regions and countries.

Figure 4 shows several examples explaining the selection of the given parameters and impact indicators. As can be seen, the average pkm travelled is not so correlated with GDP, or expenditure per head on car transport (including the purchase of vehicles, operational and services costs). Possible correlation of the fatalities (death per 100 million $\mathrm{pkm}$ ) was investigated with level of urbanization, road density (total road in $[\mathrm{km}]$ related to the land $\left[\mathrm{km}^{2}\right]$, ratio of motorways length per total road length, ratio of motorways and main national road length to total road length, etc.

As Figure 4 demonstrates, too, considerable correlation was not found. A good correlation of fatalities was identified with GDP per capita and even better correlation calculated with expenditure per head on car transport.

Another example is shown in Figure 5 that explains why the indicators ratio of young (less than 25 years) and old (more than 70 years old) car drivers were selected in this study. It is well interesting the young and old drivers are involved in more fatal accidents. Number of fatalities per 1000 accidents is slightly higher, only, while the other indicators are more significant.

Researchers (Chester, Horvath 2009; Bickel, Friedrich 2005; Tánczos, Török 2006; Ghadi et al. 2018; Mommens et al. 2018; Janic 2007; Kaddoura, Nagel 2018; Van Es- a)

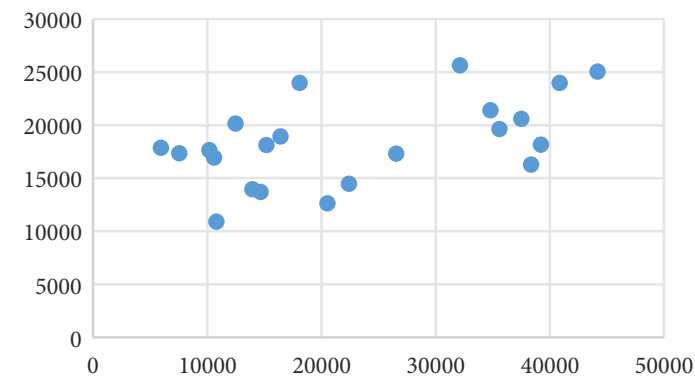

c)

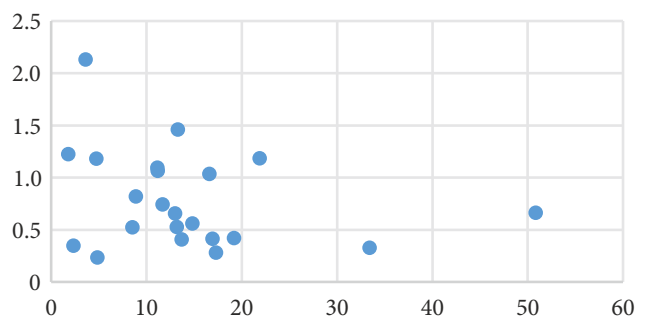

b)

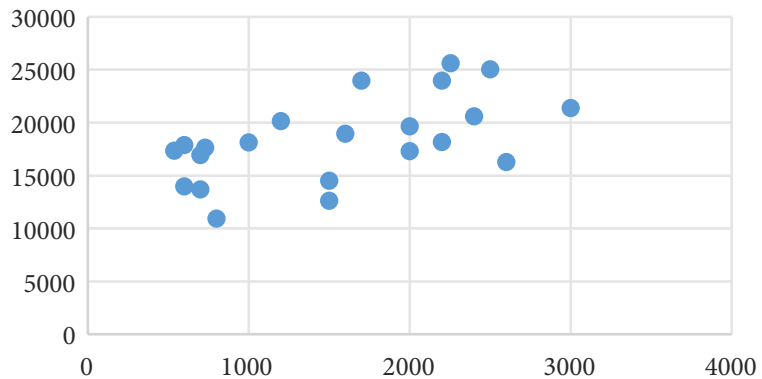

d)

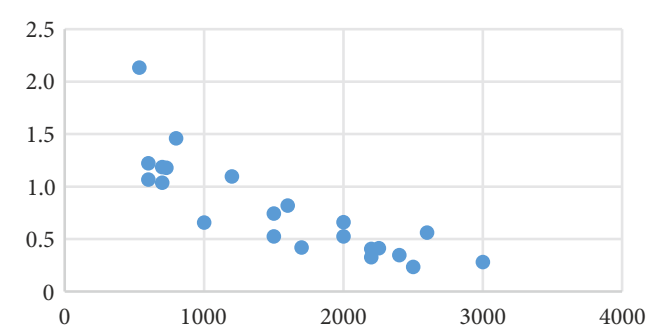

Figure 4. Several examples of the impact indicator selection studies: a - average [pkm] per car compared to GDP;

$\mathrm{b}$ - average [pkm] per car compared to the expenditure per head on car transport [€]; $\mathrm{c}$ - fatalities per 100 million $[\mathrm{pkm}]$ compared to the road density $\left[\mathrm{km} / \mathrm{km}^{2}\right]$;

$\mathrm{d}$ - fatalities per 100 million [pkm] compared g to the expenditure per head on car transport [€] (redrawn by use of data from Rigo et al. (2007))

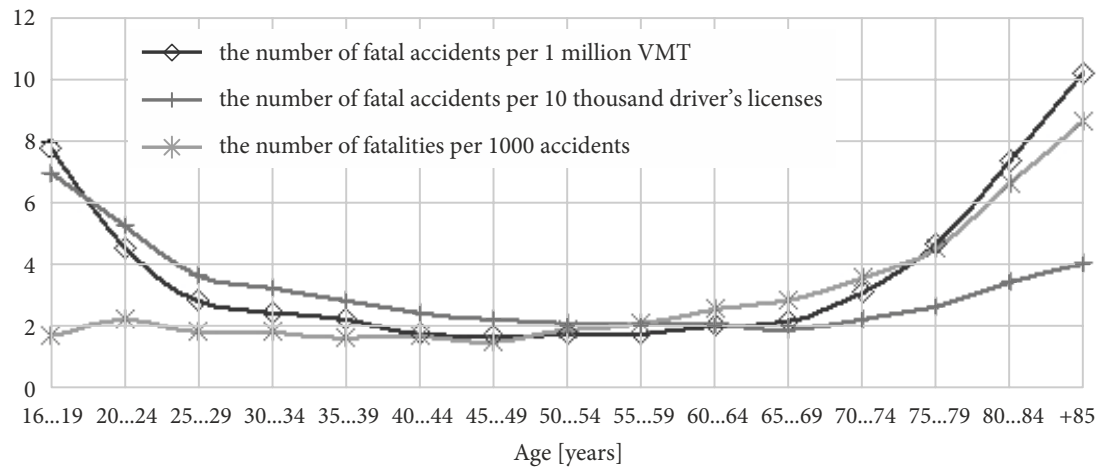

Figure 5. Fatal accidents according to the age distribution of drivers (redrawn by use of data from Fazzalaro (2002) and Rohács, Palme (2010)) 
sen et al. 2011; Maibach et al. 2008; Ricardo-AEA 2014) contributing the reports had cited a large number of references. They show that there is not unique and well applicable methods for estimating the transport safety accident risks and caused external costs. The first problem of how to predict them. Even, if the country had useful accident statistics, the initial data must be corrected, because the non-reported accident (Table 1).

Table 1. Correction factors for unreported number of accident (CORDIS 2006)

\begin{tabular}{|l|c|c|c|c|c|}
\hline \multicolumn{1}{|c|}{ TM } & Fatality & $\begin{array}{c}\text { Severe } \\
\text { injury }\end{array}$ & $\begin{array}{c}\text { Slight } \\
\text { injury }\end{array}$ & $\begin{array}{c}\text { Average } \\
\text { injury }\end{array}$ & $\begin{array}{c}\text { Damage } \\
\text { only }\end{array}$ \\
\hline Car & 1.02 & 1.25 & 2 & 1.63 & 3.5 \\
\hline $\begin{array}{l}\text { Motorbike/ } \\
\text { moped }\end{array}$ & 1.02 & 1.33 & 3.2 & 2.38 & 6.5 \\
\hline Bicycle & 1.02 & 2.75 & 8 & 5.38 & 18.5 \\
\hline Pedestrian & 1.02 & 1.35 & 2.4 & 1.88 & 4 \\
\hline
\end{tabular}

\section{Investigation on the accident outcomes}

The consequences, as outcomes of traffic accidents, might be defined relatively easy, while calculation of the costs associated by these outcomes is sufficiently more complex and hard problem.

The accident consequences might be classified into three groups:

- human injuries, namely fatality, severe injury and slight injury;

- damages including the damages in cars, in transport infrastructures, as road structural damages, damages in traffic control systems, losses of products or production capacity (for example due to damage the electric supporting system, damage of production supplying materials) and other damages like damages inbuilt (houses, electric lines, etc.) and nature environments, cultural heritages;

- societal consequences as, cost of accident investigation medical costs, administrative and juridical processes' costs, traffic congestions, extra expenditure of relatives and friends of the injured people.

Here some thoughts about the estimation of the costs associated with human injuries.

There is a covenant in references; the injuries are classified as a fatality, severe and slight injuries. Probably the most common and well used by Chester, Horvath (2009); Bickel, Friedrich (2005); Tánczos, Török (2006); Ghadi et al. (2018); Mommens et al. (2018); Janic (2007); Kaddoura, Nagel (2018); Van Essen et al. (2011); Maibach et al. (2008); Ricardo-AEA (2014) and definition introduced by Nellthorp et al. (1998):

- fatality: death during the accident or within 30 days after an accident;

- serious injury: casualties require hospital treatments and have lasting injuries;

- slight injury: casualties whose injuries do not require hospital treatment or only a short staying in hospitals;

- damage only accident: accident without casualties.

The Commission Directive 2014/88/EU (EC 2014) defines the conventional safety indicators (for railway transport) and common methods of calculating accident costs. For example, it introduces the following indicators to calculate the economic impact of accidents as total in $[€]$ and relative to [train-km]:

- number of deaths and serious injuries multiplied by the VPC;

- cost of damages to the environment;

- cost of material damages to rolling stock or infrastructure;

- cost of delays as a consequence of accidents.

The Commission Directive 2014/88/EU (EC 2014) state on that, the "safety authorities shall report the economic impact of significant accidents. The VPC is the value society attributes to the prevention of a casualty and as such shall not form a reference for compensation between parties involved in accidents". The Commission Directive 2014/88/EU (EC 2014) defines the other relevant indicators and terms, too. For instant, the "significant damage to stock, track, other installations or environment" means damage that is equivalent to $€ 150000$ or more; or "extensive disruptions to traffic" means that train services on the main railway line are suspended for six hours or more. The costs associated with transport accidents might be estimated by VPC. The Commission Directive 2014/88/EU (EC 2014) states the VPC is composed of:

- value of safety per se: that can be estimated by WTP values;

- direct and indirect economic costs containing the (1) medical and rehabilitation costs, (2) legal court cost, cost for police, private crash investigations, the emergency service and administrative costs of insurance, and (3) production losses: value to society of goods and services that could have been produced by the person if the accident had not occurred.

This approach is well similar with methodology applied by the European international studies (Chester, Horvath 2009; Bickel, Friedrich 2005; Tánczos, Török 2006; Ghadi et al. 2018; Mommens et al. 2018; Janic 2007; Kaddoura, Nagel 2018; Van Essen et al. 2011; Maibach et al. 2008; Ricardo-AEA 2014; CORDIS 2006; Bickel et al. 2006). One of the latest excellent cost estimation (Ricardo-AEA 2014) uses the following costs are related to the accident risk:

- expected cost (of death and injury) due to an accident for the person exposed to risk;

- expected cost for the relatives and friends of the person exposed to risk;

- accident cost for the rest of the society (output loss, material costs, police and medical costs).

These costs can be determined even for risk of each vehicle and road types with taking into account the traffic flow intensity and internal costs. 
The costs related to the death as cost for relatives and friends as usually are estimated by use of the WTP method (Andersson 2007). As it can be seen in Table 2. The costs of fatalities that the people willing to pay for avoiding fatal accidents are not harmonized with the net income of people or GDP per capita (Figure 6).

It hasn't been identified any economic drivers that might be applied for determining the values of accident fatality avoidance or as it is called, too, the value of statistical life. On the other hand, the fatality cost reaches the net income owned for 70 up to 200 years. People having smaller incomes willing to pay the larger sum for their life. It is interesting, the willingness is rather greater in case of countries having less GDP. It seems the fatality costs are overestimated. The people willing to pay money that they have not in their hand. Another interesting question, the people travelling as usually by train or people using their personal car are willing to pay the same amount of money for avoiding the fatal accident?

In any case, the fatality costs estimated for different countries are correlated with the GDP (Rohács, J., Rohács, D. 2020).

This study used the adapted costs that were determined from Table 2. The values were increased proportionally with GDP growth and corrected by the dynamics of changes in net incomes using the model from (Rohács, J., Rohács, D. 2020).

Another example investigated is the congestion cost. This cost is calculated as cost related to the unit of [vkm] (Figure 6). The cost intensively depends on the regions, urban road and population density, types of vehicles, capacities of the road systems, etc. The applied methodologies are based on the capacity ratio (number of vehicles on given time related to the maximum capacity of the road) and value of time. The models might be used for calculating the cost of people travelling in cars. This method seems too complex. The cost of congestion depends on the type of roads, traffic intensity, weather condition, etc. and the calculation required detailed modelling. This study has applied a more straighforward method, calculating at first the yearly delay in travelling because of the congestions. There were estimated increasing in travelling times for each day of travelling and the number of appearing the congestion because of the overcapacity traffic. The value of congestion was determined by use of time estimated for congestions multiplied by the number of travellers in the vehicle and value of time and divided by the annual vehicle running distance.

During developing the methodology shortly described here, there were identified two incompletions: (1) effect of the congestion on the accident risks (Quddus et al. 2010) and (2) delay in travels because of the accidents or congestions initiated by accidents. Of course the effect on the accident risk might be taken into account in generally applied risks. The delays due to the accidents are recommended to include in the accident consequences. It might be calculated as a number of people and cars affected by the traffic flow reduction and delays multiple by increased travel time and people value of time and cars' operating costs (separately).

Finally, some comments on the applicability of developing methods. The calculation really must be adapted to the objectives of the investigations and the possible way of selecting or determining the required inputs. For instant, the Hungary accident statistics for the year 2014 (Table 3) demonstrate, road transport is a leading contributor to transport safety external costs. However, in rail accidents, 135 cases was caused by collisions with persons.

According to the Hungarian statistics (KSH 2015) the ratio of the accident with damage only (without people injury) about $8 \%$ for rail, around $14 \%$ for water and reaches the $40 \ldots 45 \%$ for road passenger car transport.

Table 2. Some economic drivers and estimated values for casualties avoided

(Ricardo-AEA 2014; World Bank 2018) for the year 2010

\begin{tabular}{|l|c|c|c|c|c|c|}
\hline \multicolumn{1}{|c|}{ Country } & GDP per capita [\$] & Net income [\$] & Gini index & Fatality [€] & Severe injury [€] & Slight injury [€] \\
\hline Latvia & 10743 & 8779 & 35.27 & 1034000 & 140000 & 10000 \\
\hline Estonia & 14062 & 10683 & 32.16 & 1163000 & 155800 & 11200 \\
\hline Slovakia & 16062 & 10897 & 24.94 & 1593000 & 219700 & 15700 \\
\hline Slovenia & 22942 & 21572 & 35.79 & 1989000 & 258300 & 18900 \\
\hline Greece & 25851 & 21382 & 34.48 & 1518000 & 198400 & 15100 \\
\hline Spain & 29956 & 27052 & 26.81 & 1913000 & 237800 & 17900 \\
\hline Italy & 33761 & 27809 & 34.41 & 1916000 & 246200 & 18800 \\
\hline France & 39186 & 33892 & 33.78 & 2070000 & 289200 & 21600 \\
\hline Germany & 40164 & 32754 & 31.14 & 2220000 & 307100 & 24800 \\
\hline Belgium & 43000 & 38879 & 28.53 & 2178000 & 330400 & 21300 \\
\hline Finland & 43864 & 36693 & 27.74 & 2213000 & 294300 & 22000 \\
\hline Austria & 44916 & 36416 & 30.25 & 2395000 & 327000 & 25800 \\
\hline Ireland & 46019 & 46917 & 32.30 & 2412000 & 305600 & 23300 \\
\hline Netherlands & 46623 & 42711 & 28.73 & 2388000 & 316400 & 25500 \\
\hline
\end{tabular}




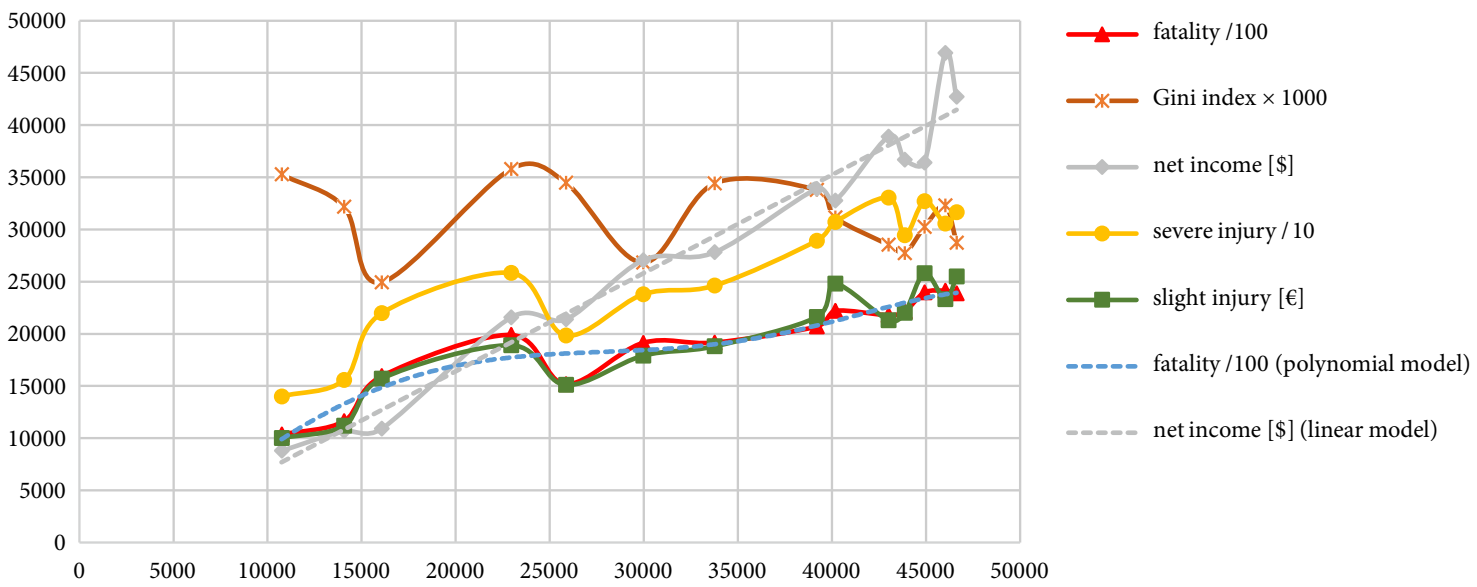

Figure 6. Some economic factors and cost of accident casualties as function of GDP

Table 3. Accident data for Hungary year 2014 (KSH 2015)

\begin{tabular}{|l|c|c|c|c|}
\hline Number of & Road & Rail & Water & Air \\
\hline accidents with human injures & 15847 & 180 & 3 & 30 \\
\hline persons injured in accident & 20124 & 94 & 0 & 27 \\
\hline persons killed in accidents & 626 & 108 & 3 & 4 \\
\hline
\end{tabular}

\section{Finalizing the methodology and some results}

The introduced TIPI and the created methodology for its calculations supported by a developed Excel table have been used in testing and concept validation. After preliminary calculations and testing, there were identified two significant problems with the table developing for calculating the introduced TIPI. At first, as it was found, the parameters and indicators describing, defining the elements of the calculation are hugely varied. They depend on not only the technical and technological performances but on economic, social factors, too. For example, it seems the accident risks somewhat higher in case of smaller expenditure per head on the car (see right bottom chart on Figure 4), that in reality depends on the average car life and conditions. However, the maximum values on the chart belong to countries having so-called too dynamic and aggressive drivers (drivers with higher soft skills, i.e drivers do not follow the traffic rules and traffic safety recommendation). So, the parameters and indicators cannot be preliminarily defined precisely. Another problem is associated by a lack of information on required inputs because of unavailability of statistical data or detecting reliability problem with available inputs.

There were made two improvements: (1) the table containing the recommended structure and methodology of using the preliminary defined parameters and indicators has opened from the top, namely, the users may include additional particular parameters and/or indicators for investigating the special regions, (2) introducing the models estimated from available data for similar regions or investigated cases.
In this study, the inputs were identified, analysed and selected from the references cited in this paper. The country-specific inputs were added from national statistical sources. Principally, the national statistical offices publish more detailed information on accident statistics (see for example for Hungarian data (KSH 2015)) and generally on transport. In required cases, the similar region having similar performances were selected, and the approximation models were determined from the available data for similar regions. As an example, the risk of accident $p$ for countries similar to Hungary can be determined by use equation:

$$
P=\frac{\left(a_{1}+a_{2} \cdot e^{\frac{p_{1}}{a_{3}}}\right) \cdot p_{3}}{p_{2}},
$$

where: instead of formula defined by Equation $(6) ; a_{i}$ are the model coefficients. This approximation can be used, when the GDP per capita equals to $0.8 \ldots 1.2 \mathrm{GDP}_{\mathrm{HU}}$.

Some interesting results are shown in Figures 7 and 8.

Figure 8 shows that the motorcycle vehicles have the greatest external costs induced by the safety factors because of the extremely large risk for the fatal accident and severe injury. Another very interesting fact, the congestion, that as usual the researchers include into the safety area generates the determining parts of the impact external costs. (Actually, the high value of congestion calculated for freight transport is "great" because it is related to the $1 \mathrm{tkm}$ that equals about to $10 \mathrm{pkm}$ ). Notably, authors of this paper in position, the congestion must be taken into account in sub-system transport support, because it more depends on the flow management than on the safety factors. Of course, the increases in accidents risks because the congestion must be calculated as part of accident risks.

Figure 9 demonstrates how the developing method can be applied in comparison to the regional transportation systems. The relatively large difference in Hungarian and European safety TIPI can be explained by (1) higher accident risks at Hungary depending on the GDP (when GDP 


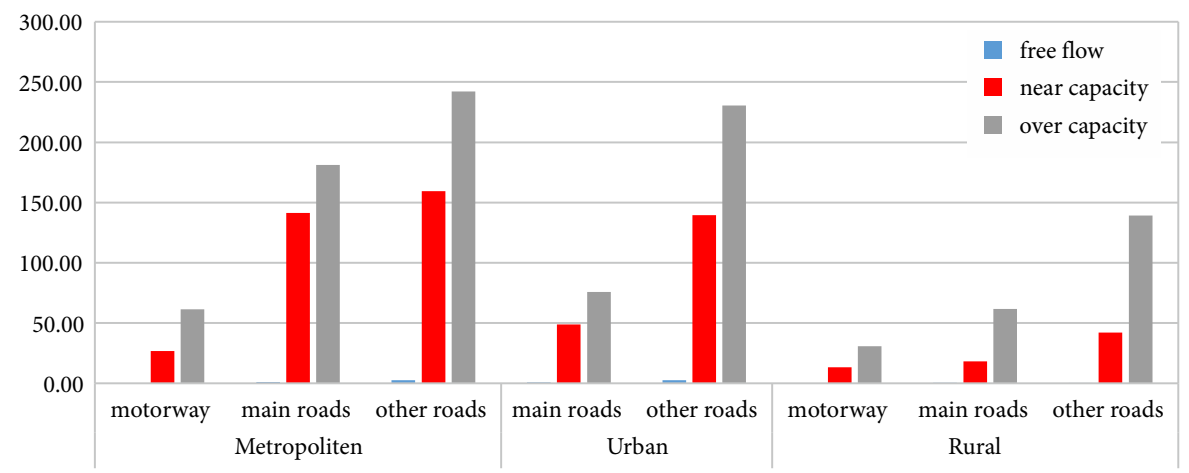

Figure 7. Congestion cost [€ ct/vkm] recommended to apply by Quddus et al. (2010)

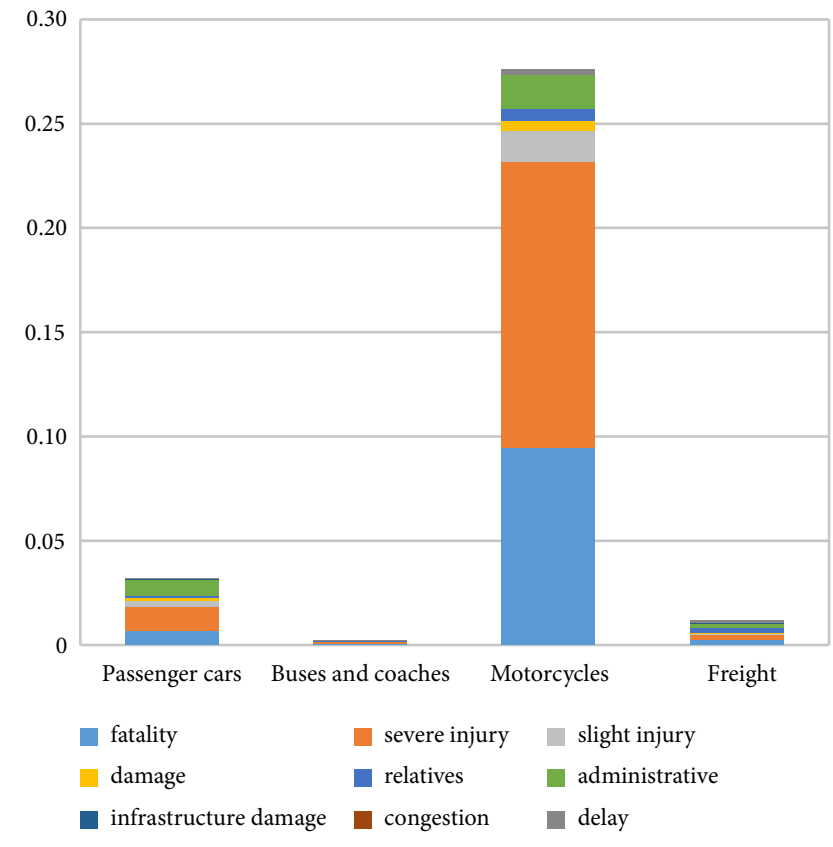

Figure 8. Safety TIPI calculated for average European road transport for year 2014 (in [€/pkm] and [€/1 tkm] for freight transport)

is smaller, risk is more significant (Rohács, J., Rohács, D. 2020)), (2) lower social cost of fatalities and severe injury), (3) lower value of time (about 2.5 times less), (4) less congestion marginal external costs, (5) less time and cost of administrative works induced by accidents and (6) relatively older fleets of vehicles in Hungary.

Figures 8 and 9 show the results for the year 2014. This calculation can be realized on a broder form. At first, calculating for pasts years. At second, the same calculation can be applied for predicted time (when the inputs must be selected from the technology foresight and transport forecasts). At third, the index must be calculated as a weighted average for the transport depending on the vehicle type and age compositions.

\section{Conclusions}

Nowadays, in the era of climate change, sustainability is a primary objective of developing future vehicles and

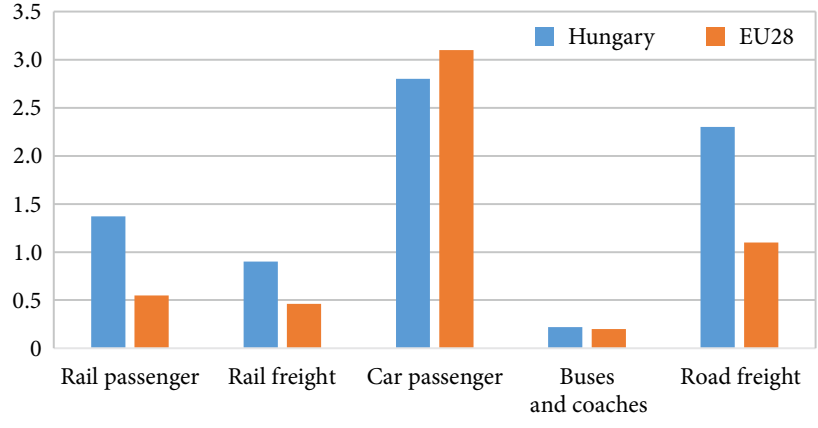

Figure 9. Safety total impacts performance index, i.e. external costs generated by the safety impacts in year 2014

(the costs induced by congestions are excluded) ([€ ct/pkm] and $[€ \mathrm{ct} / 0.1 \mathrm{tkm}])$

transportation systems. There are several significant international (EU supported) projects were dealing with the estimation of the transport impacts. After evaluation of the environmental impacts, several projects and researchers had developed models based on the calculation of the externality. They were taken into account the safety, upstream and downstream processes, congestions, biodiversity, etc.

This paper follows the developing total impact evaluation methodology and creates a unique Excel table for its application. The method has several advantages as (1) uses a special TIPI evaluated by calculating the total costs including the operational and all the external costs in (2) form of TLCCs related to the unit of work done by the vehicles, while (3) the calculation methodology is well defined and applicable and (4) usable in case of lack of initial information, too (by determining the required inputs from available statistics of the similar regions, cases).

The developing methodology was tested for concept validation calculations. In this paper, in particular, the safety aspect of road and rail transport was calculated. These calculations must be adapted according to the objectives of investigations. It is to be noted that for example, since congestion increases accident risks, it is included in safety calculations and would also be included in subsystem transport support calculation in this emerging methodology. It is also possible to add specific indicators/ parameters column in the Excel table. 
The results were compared to the available information. The results show that the developed methodology user- friendly can be applied for evaluating the total impacts of transport vehicles, transport companies, regional transport systems, and TMs. Transportation-related data are sometimes unavailable or limited depending on with, the economy and society development, the related technology progress and the accessibility and affordability. This methodology adapts to accept inputs from regions of the same characteristics in terms of economic, social, geographical and technical factors as the investigated region and results to reliable/acceptable results.

Further works will include calculations of other SGIs for a different mode of transport and realizing forecasts results based on the calculated historical data.

\section{Acknowledgements}

This work was supported by Hungarian National Project EFOP-3.6.1-16-2016-00014 "Investigation and Development of the Disruptive Technologies for e-Mobility and their ntegration into the Engineering Education (IDEA-E)".

\section{Disclosure statement}

Authors declare no conflict of interest.

\section{References}

ACARE. 2001. Meeting Society's Needs and Winning Global Leadership. Report of the Group of Personalities. Advisory Council for Aeronautics Research in Europe (ACARE). 26 p. Available from Internet:

https://www.acare4europe.org/documents/vision-2020

ACARE. 2017. Strategic Research \& Innovation Agenda. 2017 Update. Volume 1. Advisory Council for Aviation Research and Innovation in Europe (ACARE). 100 p. Available from Internet: https://www.acare4europe.org/sites/acare4europe. org/files/document/ACARE-Strategic-Research-InnovationVolume-1.pdf

Anas, A.; Lindsey, R. 2011. Reducing urban road transportation externalities: road pricing in theory and in practice, Review of Environmental Economics and Policy 5(1): 66-88. https://doi.org/10.1093/reep/req019

Andersson, H. 2007. Willingness to pay for road safety and estimates of the risk of death: Evidence from a Swedish contingent valuation study, Accident Analysis \& Prevention 39(4): 853-865. https://doi.org/10.1016/j.aap.2006.12.008

Bickel, P.; Friedrich, R. (Eds.). 2005. ExternE: Externalities of Energy: Methodology 2005 Update. European Commision. 287 p.

Bickel, P.; Friedrich, R.; Burgess, A.; Fagiani, P.; Hunt, A.; De Jong, G.; Navrud, S. 2006. HEATCO: Developing Harmonised European Approaches for Transport Costing and Project Assessment. Deliverable 6: Case Study Results. Contract No FP6-2002-SSP-1/502481. Institute of Energy Economics and Rational Energy Use, University of Stuttgart, Germany. 45 p.

Bicsák, G.; Hornyák, A.; Veress, Á. 2012. Numerical simulation of combustion processes in a gas turbine, AIP Conference Proceedings 1493: 140-148. https://doi.org/10.1063/1.4765482

BTS. 2018. Bureau of Transportation Statistics. US Department of Transportation, Washington, DC, US. Available from Internet: https://www.bts.gov
Chester, M. V.; Horvath, A. 2009. Environmental assessment of passenger transportation should include infrastructure and supply chains, Environmental Research Letters 4(2): 024008. https://doi.org/10.1088/1748-9326/4/2/024008

CORDIS. 2006. HEATCO: Developing Harmonised European Approaches for Transport Costing and Project Assessment. 6th RTD Framework Programme. Community Research and Development Information Service (CORDIS). Available from Internet: https://cordis.europa.eu/project/id/502481

Csikós, A.; Varga, I.; Hangos, K. M. 2015. Modeling of the dispersion of motorway traffic emission for control purposes, Transportation Research Part C: Emerging Technologies 58: 598-616. https://doi.org/10.1016/j.trc.2015.03.027

De Ceuster, G.; Van Herbruggen, B.; Logghe, S.; Proost, S. 2004. TREMOVE 2.2: Model and Baseline Description. Report for European Commission. Service Contract B43040/2002/342069/MAR/C.1. 156 p. Available from Internet: https://www.asser.nl/upload/eel-webroot/www/documents/ TREMOVEreport.pdf

Dobranskyte-Niskota, A. M.; Perujo, A.; Pregl, M. 2007. Indicators to Assess Sustainability of Transport Activities. Part 1: Review of the Existing Transport Sustainability Indicators Initiatives and Development of an Indicator Set to Assess Transport Sustainability Performance. Institute for Environment and Sustainability, Joint Research Centre, European Commission. EUR 23041 EN. 59 p. https://doi.org/10.2788/54736

EC. 2011a. Commission Staff Working Paper: Impact Assessment Accompanying document to the White Paper: Roadmap to a Single European Transport Area - Towards a Competitive and Resource Efficient Transport System. SEC(2011) 358 Final, Brussels, 28 March 2011. European Commission (EC). 171 p. Available from Internet: https://eur-lex.europa.eu/LexUriServ/LexUriServ.do?uri=SEC:2011:0358:FIN:EN:PDF

EC. 2011b. Flightpath 2050: Europe's Vision for Aviation: Maintaining Global Leadership and Serving Society's Needs. European Commission (EC). 32 p. https://doi.org/10.2777/50266

EC. 2011c. White Paper on Transport: Roadmap to a Single European Transport Area: Towards a Competitive and Resource Efficient Transport System. European Commission (EC). 32 p. https://doi.org/10.2832/30955

EC. 2014. Commission Directive 2014/88/EU of 9 July 2014 Amending Directive 2004/49/EC of the European Parliament and of the Council as Regards Common Safety Indicators and Common Methods of Calculating Accident Costs. European Commission (EC). Available from Internet: http://data.europa.eu/eli/dir/2014/88/oj

Edenhofer, O.; Pichs-Madruga, R.; Sokona, Y.; Farahani, E.; Kadner, S.; Seyboth, K.; Adler, A.; Baum, I.; Brunner, S.; Eickemeier, P.; Kriemann, B.; Savolainen, J.; Schlömer, S.; Von Stechow, C.; Zwickel, T.; Minx J. C. (Eds.). 2014. Climate Change 2014: Mitigation of Climate Change. Intergovernmental Panel on Climate Change (IPCC). 1454 p. Available from Internet: https://www.ipcc.ch/report/ar5/wg3

EU. 2016. Statistical Pocketbook 2016: EU Transport in Figures. Publications Office of the European Union (EU), Luxembourg. 160 p. Available from Internet: https://ec.europa.eu/ transport/facts-fundings/statistics/pocketbook-2016_en

Eurostat. 2018. European Statistics. Available from Internet: https://ec.europa.eu/eurostat/data/database/information

Fazzalaro, J. J. 2002. Elderly Driver Issues. OLR Research Report 2002-R-0021. Office of Legislative Research (OLR), Hartford, CT, US. Available from Internet: https://www.cga.ct.gov/2002/ olrdata/tra/rpt/2002-R-0021.htm

Furch, J. 2016. A model for predicting motor vehicle life cycle cost and its verification, Transactions of FAMENA 40(1): $15-26$. 
Ghadi, M.; Török, Á.; Tánczos, K. 2018. Study of the economic cost of road accidents in Jordan, Periodica Polytechnica Transportation Engineering 46(3): 129-134.

https://doi.org/10.3311/PPtr.10392

Hellgren, J. 2007. Life cycle cost analysis of a car, a city bus and an intercity bus powertrain for year 2005 and 2020, Energy Policy 35(1): 39-49. https://doi.org/10.1016/j.enpol.2005.10.004

Horvath, A.; Matthews, H. S. 2005. Sustainability of transportation and other infrastructure systems, Journal of Infrastructure Systems 11(1): 1-1.

https://doi.org/10.1061/(ASCE)1076-0342(2005)11:1(1)

Janic, M. 2007. Modelling the full costs of an intermodal and road freight transport network, Transportation Research Part D: Transport and Environment 12(1): 33-44. https://doi.org/10.1016/j.trd.2006.10.004

Jun, H. K.; Kim, J. H. 2007. Life cycle cost modeling for railway vehicle, in 2007 International Conference on Electrical Machines and Systems (ICEMS), 8-11 October 2007, Seoul, South Korea, 1989-1994.

Kaddoura, I.; Nagel, K. 2018. Simultaneous internalization of traffic congestion and noise exposure costs, Transportation 45(5): 1579-1600. https://doi.org/10.1007/s11116-017-9776-0

KSH. 2015. Közlekedési baleseti statisztikai évkönyv, 2014 [Statistical Yearbook of Traffic Accidents, 2014]. Központi Statisztikai Hivatal (KSH) [Hungarian Central Statistical Office]. 133 o. Available from Internet: https://www.ksh.hu/docs/hun/xftp/ idoszaki/baleset/baleset14.pdf (in Hungarian).

Litman, T. 2019. Well Measured Developing Indicators for Sustainable and Livable Transport Planning. Victoria Transport Policy Institute, Victoria, Canada. 110 p. Available from Internet: https://www.vtpi.org/wellmeas.pdf

Maibach, M.; Schreyer, C.; Sutter, D.; Van Essen, H. P.; Boon, B. H.; Smokers, R.; Schroten, A.; Doll, C.; Pawlowska, B.; Bak., M. 2008. Handbook on Estimation of External Costs in the Transport Sector. Produced within the Study Internalisation Measures and Policies for All external Cost of Transport (IMPACT). Version 1.1. CE Delft, The Netherlands. 336 p. Available from Internet: https://ec.europa.eu/transport/sites/transport/files/themes/sustainable/doc/2008_costs_handbook.pdf

Messagie, M.; Lebeau, K.; Coosemans, T.; Macharis, C.; Van Mierlo, J. 2013. Environmental and financial evaluation of passenger vehicle technologies in Belgium, Sustainability 5(12): 5020-5033. https://doi.org/10.3390/su5125020

Mommens, K.; Lebeau, P.; Verlinde, S.; Van Lier, T.; Macharis, C. 2018. Evaluating the impact of off-hour deliveries: an application of the transport agent-based model, Transportation Research Part D: Transport and Environment 62: 102-111. https://doi.org/10.1016/j.trd.2018.02.003

Nellthorp, J.; Mackie, P.; Bristow, A. 1998. EUNET: Socio-Economic and Spatial Impacts of Transport. Deliverable D9: Measurement and Valuation of the Impacts of Transport Initiatives. Contract: ST-96-SC.037. Institute for Transport Studies, University of Leeds, UK. 159 p. Available from Internet: https:// ec.europa.eu/environment/archives/tremove/pdf/measurement_maintext.pdf

OECD. 2018. OECD Environmental Data and Indicators. Organisation for Economic Co-operation and Development (OECD). Available from Internet: http://www.oecd.org/env/ indicators-modelling-outlooks/data-and-indicators.htm

Quddus, M. A.; Wang, C.; Ison, S. G. 2010. Road traffic congestion and crash severity: econometric analysis using ordered response models, Journal of Transportation Engineering 136(5): 424-435.

https://doi.org/10.1061/(ASCE)TE.1943-5436.0000044
Ricardo-AEA. 2014. Update of the Handbook on External Costs of Transport. Final Report Ricardo-AEA/R/ED57769. 139 p. Available from Internet: https://ec.europa.eu/transport/sites/ transport/files/themes/sustainable/studies/doc/2014-handbook-external-costs-transport.pdf

Rigo, N.; Hekkenberg, R.; Ndiaye, A. B.; Hadhazi, D.; Simongati, G.; Hargitai, C. 2007. Performance assessment for intermodal chains, European Journal of Transport and Infrastructure Research 7(4): 283-300.

https://doi.org/10.18757/ejtir.2007.7.4.3400

Rohacs, D.; Rohacs, J. 2016. Magnetic levitation assisted aircraft take-off and landing (feasibility study - GABRIEL concept), Progress in Aerospace Sciences 85: 33-50.

https://doi.org/10.1016/j.paerosci.2016.06.001

Rohacs, D.; Voskuijl, M.; Rohacs, J.; Schoustra, R.-J. 2013. Preliminary evaluation of the environmental impact related to aircraft take-off and landings supported with ground based (MAGLEV) power, Journal of Aerospace Operations 2(3-4): 161-180. https://doi.org/10.3233/AOP-140040

Rohacs, J. 2010. Evaluation of the air transport efficiency definitions and their impact on the European personal air transportation system development, Transactions of the Institute of Aviation 205: 14-32.

Rohács, J.; Palme, R. 2010. Some thoughts on fatal road accidents, in Proceedings of the 2010 International Symposium on Safety Science and Technology, 26-29 October 2010, Hangzhou, China, Part B: 1917-1930.

Rohács, J.; Rohács, D. 2020. Total impact evaluation of transportation systems, Transport 35(2): 193-202.

https://doi.org/10.3846/transport.2020.12640

Rohács, J.; Simongáti, G. 2007. The role of inland waterway navigation in a sustainable transport system, Transport 22(3): 148-153. https://doi.org/10.3846/16484142.2007.9638117

Santero, N.; Masanet, E.; Horvath, A. 2010. Life Cycle Assessment of Pavements: a Critical Review of Existing Literature and Research. Prepared with the support of the Portland Cement Association through the Department of Energy under Contract No DE-AC02-05CH11231. University of California, US. 88 p. Available from Internet: https://escholarship.org/uc/item/8632v9cc

Santos, G.; Behrendt, H.; Maconi, L.; Shirvani, T.; Teytelboym, A. 2010. Part I: externalities and economic policies in road transport, Research in Transportation Economics 28(1): 2-45. https://doi.org/10.1016/j.retrec.2009.11.002

Tánczos, K.; Török, Á. 2006. Estimation method for emission of road transport, Periodica Polytechnica Transportation Engineering 34(1-2): 93-100.

Van Essen, H.; Scroten, A.; Otten, M.; Sutter, D.; Schreyer, C.; Zandonella, R.; Maibach, M.; Doll, C. 2011. External Costs of Transport in Europe: Update Study for 2008. CE Delft, The Netherlands. 163 p. Available from Internet: http://www.cer. be/sites/default/files/publication/2312_External_Costs_update_study_FINAL.pdf

Wangai, A.; Kale, U.; Kinzhikeyev, S.; Tekbas, M. B., Rohacs, J. 2017. Influence of e-mobility on total impact of the transport means, in IFFK 2017 Innováció és fenntartható felszíni közlekedés, 30 August - 1 September 2017, Budapest, Hungary, 94-100.

WCED. 1987. Our Common Future. World Commission on Environment and Development (WCED). Oxford University Press. 383 p.

World Bank. 2018. World Bank Open Data. Available from Internet: https://data.worldbank.org

WRI. 2018. CAIT Climate Data Explorer. World Resources Institute (WRI), Washington, DC, US. Available from Internet: http://cait.wri.org 